\title{
Is the timed up and go (TUG) sensitive to differentiating patients with mild to moderate PD compared to age matched controls: a descriptive pilot study
}

\begin{abstract}
Background: As the population ages, an increasing number of individuals are diagnosed with Parkinson's Disease (PD), a complex, progressive, neurodegenerative motor and nonmotor disorder which can compromise quality of life/ independence. Given there are no laboratory tests to rule in the disorder, the diagnosis may be delayed until $85 \%$ of the dopamine neurons are degenerated. Could the clinical Timed $\mathrm{Up}$ and Go (TUG) test serve as an inexpensive, clinical biomarker to help physicians make a diagnosis of PD?
\end{abstract}

Methods: This descriptive, cross sectional evaluation study included 30 participants (15 with mild to moderate PD [Hoehn and Yahr I-II] and 15 age matched controls. Dependent variables included gender, age, self-reported motor and non-motor impairments paired with standardized measurements of mobility, balance (TUG) and cognition. Seventy percent of participants returned to be tested with the instrumental, dual task TUG (i TUG), the Five Times Sit to Stand Test (FTSTS) and 360o turning. Dependent variables were described (mean and standard deviation) and group differences tested for significance with the Two Sample T Test $(\mathrm{P}<0.05)$.

Results: TUG performance was within normal limits with no significant differences between the two groups ( 7.28 seconds age matched controls and 7.60 seconds PD). In addition, no significant differences were found between the two groups relative to gender, age, pain, fall history or gait speed. However, age matched controls were significantly less depressed, had better balance confidence but reported significantly less physical activity, more medical problems and more prescription medications.

Discussion \& conclusion: The TUG was not a clinically sensitive biomarker to distinguish age matched healthy participants from those with mild-moderate PD who exercised aggressively. The dual task instrumental iTUG variant of the TUG may be more sensitive as a clinical biomarker for distinguishing individuals with early PD from age matched controls.

Keywords: diagnosis of Parkinson's disease, timed up and go, clinical biomarker of pd
Volume 3 Issue 2 - 2018

\author{
Byl N,' Henry R, ${ }^{2}$ Rizzo R, ${ }^{3}$ Blum D ${ }^{4}$ \\ 'Department of Physical Therapy and Rehabilitation Science, \\ UCSF School of Medicine, USA \\ 2Department of Neurology, UCSF School of Medicine, USA \\ ${ }^{3}$ Department Graduate Student in the UCSF Graduate \\ Division, UCSF/SFSU Graduate Program in Physical Therapy, \\ USA \\ ${ }^{4}$ Neurologist and Specialist in Parkinson's disease in the \\ Pennisula Private Neurology Practice, USA
}

Correspondence: Nancy Byl, Department of Physical Therapy and Rehabilitation Science, Professor Emeritus in the UCSF School of Medicine, USA, Tel +4I55। 448I6, Fax 4I55I448I7,Email ByIN@ucsf.edu

Received: March 28, 2018| Published: April 04, 2018

\section{Introduction}

As our population ages, there is an increasing incidence and prevalence of Parkinson's disease (PD). In the United States, the number of persons with Parkinson's disease is expected to increase from the approximately 340,000 in 2005 to 610,000 in 2030. ${ }^{1-4}$ Parkinson's disease is a neurodegenerative condition related to a decrease in dopamine neurons in the substantia nigra. ${ }^{5,6}$ By the time a diagnosis is made, there is a loss of up to $50-80 \%$ of striatal dopaminergic innervation..$^{7-10}$ The underlying disease process of Parkinson's disease involves destruction of neurons as a consequence of accumulation of protein alpha-synuclein. ${ }^{9}$ There is progressive damage to the neural networks in the locus coeruleus, pedunculopontine nucleus (PNN), amygdala, cortical grey matter, peripheral autonomic nerves, as well as the substantia nigra pars compacta. ${ }^{7,9}$ This neuroanatomical complexity leads to considerable challenges for effective management. ${ }^{11}$
PD is primarily a clinical diagnosis based on a range of motor and non-motor signs and symptoms. Motor signs range from imbalance, festinating gait, asymmetrical arm swing, resting tremor and selfreported stiffness, freezing, falling and loss of balance confidence. ${ }^{12-14}$ Individuals also self-report many non-motor symptoms ranging from sleep disturbance, gastro intestinal discomfort, depression, anxiety, apathy, autonomic dysfunction, cognitive decline, behavioural changes, and loss of sense of smell to name among a few..$^{15}$ The impairments are difficult to manage ${ }^{13}$ leading to higher mortality, disability and dementia than in age matched controls. ${ }^{16,17}$ The lack of clear clinical biomarkers for PD has made it difficult to make an early diagnosis, objectively monitor response to treatment and minimize secondary complications such as falling, physical immobility, depression, loss of community independence and cognitive decline. ${ }^{18,19}$

Today, the diagnosis of PD is made clinically. ${ }^{20-22}$ The diagnosis is based on a combination of objective and self-reported motor and non- 
motor factors. ${ }^{23}$ Some clinicians and scientists propose by integrating neural biomarkers and genetics, an earlier and more accurate diagnosis of PD could be made in elders and high risk populations. ${ }^{24}$ It is possible; an early diagnosis could lead to more effective nonpharmacological management strategies as well as delay the need for medications and possibly deep brain stimulation. ${ }^{25-27}$ For example, there is increasing evidence that life style modifications (e.g. nutrition, hydration, physical exercise, sleep, stress management, social interactions, cognitive learning) can minimize the degenerative effects associated with aging and the risk of Alzheimer 's disease and PD. ${ }^{28-35}$ Preventive broad based intervention strategies may also be able to reduce excessive weight, metabolic disease, organ failure and cancer as well as maintain cardiopulmonary and musculoskeletal health, up regulate BDNF, excite dopamine neurons, increase oxygen delivery, minimize plaque deposition, maintain the length of our telomeres and stimulate adaptive cortical synaptic connections to drive positive neural plasticity and responsiveness of the nervous system in our aging population. ${ }^{36-41}$

When the diagnosis of PD is confirmed, the primary intervention includes a prescription of dopaminergic medications. The objective of treatment is to minimize the motor and non-motor signs/symptoms of $\mathrm{PD}$, prevent physical inactivity, decrease falls, provide neuro protection and maintain functional independence despite potential disease progression. While medications address some of the motor and non-motor symptoms of the disease, these medications can become addictive $^{42}$ and they do not predictably produce disease modifying effects. ${ }^{43}$ In fact, while some of the motor and non-motor symptoms of Parkinson's disease are improved with dopaminergic therapy, others are minimally altered (e.g. depression, gastrointestinal dysfunction, orthostatic hypotension, cognitive dysfunction, freezing of gait, balance) ${ }^{44}$ Further, over time, some of these medications can lead to new impairments such as dyskinesias and dystonic movements. ${ }^{45,46}$

While there is increasing evidence PD is associated with early changes in neural structure, at this time, bio imaging is not considered a traditional diagnostic test for PD. Although informative structural information can be obtained from magnetic resonance imaging and $\mathrm{F}=$ dopa $\mathrm{PE}$, it is not clear which imaging markers are most reliable for assessing clinical severity and rate of progression for PD. ${ }^{47-51}$ Consequently, clinicians are left making the diagnosis of PD based on a thorough history, a detailed physical examination and clinical measurements.

Clinical measurements of balance are usually administered as part of the diagnostic procedures for PD. These measurements are also used to monitor the effectiveness of different intervention strategies. Thus, clinicians need reliable and sensitive clinical diagnostic PD measurements to facilitate the ability to make an early diagnosis of PD. The question is whether a common, standardized clinical balance test, the Timed Up and Go Test (TUG) ${ }^{52-54}$ is sensitive to discriminate individuals with mild to moderate PD (on dopaminergic medications) from healthy age matched controls. For this small pilot study, the null hypothesis was there would be no significant differences in performance on the TUG for age matched controls and individuals with mild to moderate PD managed with dopamine medications.

\section{Methods}

\section{Participants}

Individuals with mild to moderate $\mathrm{PD}$ were referred to participate in this pilot study from a neurologist in the private practice of Neurology, physical therapists in the Faculty Physical Therapy Practice and the Health and Wellness Center, University of California, San Francisco, School of Medicine (UCSF) and neurologists caring for patients in the UCSF Department of Neurology, Movement Disorders Clinic. The inclusion criteria were individuals:

a. Diagnosed by a neurologist with mild to moderate PD (Hoehn and Yahr I-III) managed with dopaminergic medications.

b. 21- 80 years of age.

c. Male or female.

d. Able to come to UCSF for testing.

e. Able to understand and carry out instructions in English or come with an interpreter.

f. Walk independently with or without an assistive device.

g. Were considered medically stable relative to other health problems.

h. Did not suffer any other neurological disease.

The exclusionary criteria included individuals:

i. With a neurological disease other than PD.

ii. Medically unstable cardiovascular, pulmonary, psychiatric or medical illnesses.

iii. Unable to walk independently (with or without an assistive device).

iv. Unable to communicate in English or come with an interpreter.

Age matched control subjects were recruited from family members of participants with PD, UCSF faculty members and staff and community members who heard about the study.

This study was approved by the UCSF Committee on Human Research. Seventeen participants with mild to moderate PD and 17 healthy, age matched controls provided signed consent to participate prior to baseline testing.

\section{Measurements}

Each participant completed a series of measurements based on scales, questionnaires and a self-reported medical history. The medical history included the self-report measures including Beck Depression Scale (BDI), Activity Balance Confidence Scale (ABC), Freezing of Gait Questionnaire, (FOG) Visual Analog Scale for Pain (VAS), ${ }^{55}$ fall history in the last 3 months and the Physical Performance Test (PPT). ${ }^{43}$ In addition, standardized, performance based clinical tests of balance were administered (Timed up and Go [TUG]; selected components of the Berg Balance Scale [Functional Reach, 360o turning time, alternating foot to step, tandem standing and one foot standing with eyes open]), mobility (10 Meter Walk and Tinetti Gait Assessment. ${ }^{43,56}$ The performance tests were administered by a blinded evaluator. All participants with PD were tested "on medication". On the Tinetti Gait Assessment, one criterion was added: Symmetry of Arm Swing ( $2=$ symmetric; 1.0 near symmetric; and $0=$ absent symmetric arm swing [unilateral arm swing] bringing the total score to 14). The participants were asked to return for a second visit to complete the instrumental, dual task Timed up and Go (iTUG) $)^{57}$ and Five Times Sit to Stand (FTSTS). ${ }^{58}$

The blinded evaluator was a physical therapist or a research 
assistant trained by the physical therapist and blinded to group assignment. Defined procedures were followed for each of the standardized tests. Participants were video-taped while walking during the 10 meter walk. The videotaped evaluation was used as a reference for the evaluator and the research assistant to administer the Tinetti Gait Inventory. Each rater independently applied the Tinetti criteria for gait quality with the two scores averaged for data analysis.

Each participant who returned for additional balance testing was videotaped while performing the Itug ${ }^{57}$ with and without dual tasking (e.g. carrying a cup of water and then counting backwards). Using a lap stopwatch (Ultrak496), two research assistants, blinded to group assignment, repeatedly viewed the video tapes and timed the components until inter rater agreement was reached within 5 milliseconds for the total score.

The evaluator calculated the scores for all the independent variables. In addition, the evaluator entered the data into Excel (Microsoft) computer files. The accuracy of the scoring and the accuracy of the data entry were checked by the principal investigator.

\section{Study design and data analysis}

This was a cross sectional, study with two groups of participants. The two groups of subjects were compared descriptively on all dependent variables (mean and standard deviation). The differences in the descriptive variables for the two groups were evaluated for significance using the Two Sample Student T Test $(p<0.05)$. The primary dependent variable of interest was the TUG score (total time in seconds). The TUG scores were compared to age norms with differences between the two groups tested for significance with the Two Sample Student t Test. $(\mathrm{p}<0.05)$ Excel: Mac2011 was used for data analysis.

\section{Results}

\section{Description of differences in participant groups}

Seventeen participants with dopamine managed mild-moderate PD (H\&Y I-II) and 17 ages matched healthy participants (AMH) were recruited to the study. Two participants in each group were recruited by phone but then were unable to come for the evaluation session. Thus, 15 participants in each group completed planned study measurements. Seventy percent of the consented participants agreed to return for an additional visit for additional balance measurements (Five Times Sit to Stand and iTUG). ${ }^{59}$

For the participants with $\mathrm{PD}$, the average time since the PD diagnosis was 2.87 (2.07) years with a mean Hoehn and Yahr Scale of $1.13(0.36)$ and a mean score on the Freezing of Gait of 3.42 (11.69). All of the participants with PD had a Hoehn and Yahr scale of I or II. The age matched participants and those with PD were similar in age and gender and there were no significant differences between the two groups in terms of falls in the last 3 months, severity of pain, number of painful areas and the number of over the counter medications. However, compared to participants with PD, age matched participants self-reported significantly less depression (BDI

score of 3.0age matched controls and 6.97PD), significantly higher ABC balance score $(96.2 \%$ age matched controls versus $87.9 \% \mathrm{PD})$ and performed significantly less intense, regular physical exercise (minutes/week of 201.3 age matched controls and 316 PD). In addition, healthy age matched participants self-reported significantly more medical problems (4.27agematched and 2.89 PD) and indicated they were taking significantly more prescription drugs (4.8age matched and 2.6PD) than participants with PD (Tables 1) (Table 2).

Table I Summary of Subject Characteristics: 30 Subjects

\begin{tabular}{|c|c|c|c|}
\hline Characteristics & $\begin{array}{l}\text { Age matched } \\
\text { controls }\end{array}$ & Subjects with mild to moderate PD & Significant differences \\
\hline Number & 15 & 15 & 0 \\
\hline Age (years) Mean (SD) & $68.1(7.3)$ & $65.8(10.1)$ & Not Sign \\
\hline PD Duration Mean (SD) & 0 & $2.87(2.07)$ years & NA \\
\hline Hoehn and Yahr Level Mean (SD) & 0 & $1.13(0.36)$ years & NA \\
\hline Freezing (FOG Questionnaire)Mean ( SD) & 0 & $3.42(11.69)$ & NA \\
\hline Number of Falls in last 3 months Mean (SD) & 0 & $0.2(0.56)$ & NS \\
\hline Number of Prescription Drugs Mean (SD) & $4.8(2.27)$ & $2.6(1.8)$ & 2.14 Sign \\
\hline Number of Over counter Meds Mean (SD) & $1.93(1.83)$ & $2.4(1.4)$ & NS \\
\hline Number of Medical Diagnoses-Mean (SD) & $4.27(1.91)$ & $2.89(1.6)$ & 4.II Sign \\
\hline \multicolumn{4}{|l|}{ Specific Diagnoses } \\
\hline Heart problems & 3 & 4 & \\
\hline Diabetes & 2 & I & \\
\hline HBP & 8 & 5 & \\
\hline High Cholesterol & 2 & 0 & \\
\hline Thyroid disease & 4 & 2 & \\
\hline Lumbar problems & 4 & 5 & \\
\hline Cervical neck problems & 2 & 0 & \\
\hline
\end{tabular}




\begin{tabular}{|c|c|c|c|}
\hline Characteristics & $\begin{array}{l}\text { Age matched } \\
\text { controls }\end{array}$ & Subjects with mild to moderate PD & Significant differences \\
\hline Sleep problems & 2 & 2 & \\
\hline \multicolumn{4}{|l|}{ Cancer } \\
\hline Cancer breast & 2 & 2 & \\
\hline Cancer skin & 1 & 2 & \\
\hline Cancer Prostate & 1 & 0 & \\
\hline Cancer other & 0 & 2 & \\
\hline Migraines & I & 0 & \\
\hline Asthma & 2 & 3 & \\
\hline Allergies & 3 & 1 & \\
\hline Old fractures & 1 & 1 & \\
\hline Kidney stones & 1 & 0 & \\
\hline Labyrinthine problems & 1 & 0 & \\
\hline Depression & 0 & 3 & \\
\hline Osteoporosis & 0 & 2 & \\
\hline Pituitary problems & 0 & 1 & \\
\hline General arthritis & 0 & 2 & \\
\hline Krohn's Disease & 0 & 1 & \\
\hline Visual Analog Scale Mean ( SD) & $5.6(5.98)$ & $6.39(6.22)$ & NS \\
\hline \# Painful areas-Mean (SD) & $1.67(1.39)$ & $1.53(1.73)$ & NS \\
\hline \multicolumn{4}{|l|}{ Areas of Pain } \\
\hline Low back & 6 & 10 & \\
\hline Knee & 4 & 2 & \\
\hline Ankle & 1 & 2 & \\
\hline Shoulder & 1 & 0 & \\
\hline Neck & 4 & 5 & \\
\hline Wrist & 0 & 1 & \\
\hline Exercise Intensity (minutes/Week)Mean (SD) & $201.3(89.0)$ & $316(191.2)$ & 3.15 Sign \\
\hline
\end{tabular}

NS, not significant.

There were no differences between the groups for age and gender.Age matched controls had significantly more medical diagnoses and were taking significantly more prescription drugs than patients with mild to moderate PD. However, those with PD were exercising more intensely than age matched controls.

Table 2 Self Reported Depression, Freezing, Falls and Pain in Participants with Mild to Moderate PD and Age Matched Participants

\begin{tabular}{|c|c|c|c|c|c|c|}
\hline Outcomes & $\begin{array}{l}\text { Beck } \\
\text { depression }\end{array}$ & $\begin{array}{l}\text { Abc (\%) } \\
\text { confidence }\end{array}$ & Fog freezing & $\begin{array}{l}\text { Falls last } 3 \\
\text { months }\end{array}$ & Total vas & $\begin{array}{l}\text { \# painful } \\
\text { areas }\end{array}$ \\
\hline \multicolumn{7}{|c|}{ Age Matched Participants } \\
\hline Mean (SD) & $3.0(3.09)$ & $96.2(4.74)$ & 0 & 0 & $5.6(5.98)$ & $1.67(1.39)$ \\
\hline \multicolumn{7}{|c|}{ PD Participants } \\
\hline Mean ( SD) & $6.97(0.43)$ & $87.9(16.6)$ & $3.42(11.7)$ & $0.2(0.56)$ & $6.39(6.22)$ & $\mathrm{I} .53(\mathrm{I} .73)$ \\
\hline \multicolumn{7}{|c|}{ Difference score (Age Matched -PD) } \\
\hline Mean (SD ) & $-3.97(1.37)$ & $8.28(2.62)$ & & $-0.2(0.14)$ & $\begin{array}{l}-0.79 \\
(2.17)\end{array}$ & 0.59 \\
\hline $\mathrm{T}$ test & -2.9 & 3.16 & & -1.39 & -1.39 & 0.23 \\
\hline Significance & Significant & Significant & & NS & NS & NS \\
\hline
\end{tabular}

Participants with mild to moderate PD were more depressed and had lower balance confidence than age matched control participants. 
The age matched controls and the participants with PD performed similarly within age referenced norms in terms of gait speed $(1.46 \mathrm{~m} /$ sec [0.56)] age matched controls and 1.31 [0.49PD]). However, the quality of gait was significantly lower for participants with PD (Tinetti Gait Inventory 13.5PD and 13.9age matched controls). Performance

Table 3 Mobility and Balance Differences in Age Matched Participants and Participants with Mild to Moderate PD

\begin{tabular}{|c|c|c|c|c|c|}
\hline \multirow{2}{*}{ Performance measures } & \multirow{2}{*}{$\begin{array}{l}\text { Age matched } \\
\text { Mean (SD) }\end{array}$} & \multirow{2}{*}{$\begin{array}{l}\text { PD } \\
\text { Mean (SD) }\end{array}$} & \multirow{2}{*}{$\begin{array}{l}\text { Difference (am- } \\
\text { PD) } \\
\text { Mean (SD) }\end{array}$} & \multirow{2}{*}{$\begin{array}{l}T \\
\text { test }\end{array}$} & \multirow[t]{2}{*}{ Significance } \\
\hline & & & & & \\
\hline \multicolumn{6}{|l|}{ Mobility } \\
\hline \multicolumn{6}{|l|}{10 meter walk (fast)* } \\
\hline Seconds & $5.02(0.62)$ & $6.68(3.75)$ & $1.65(0.99)$ & -1.67 & NS \\
\hline Steps & $12.6(1.37)$ & |3.5(I.49) & $-0.92(0.52)$ & 1.75 & NS \\
\hline Step length & $0.80(0.08)$ & $0.76(0.08)$ & $0.04(0.03)$ & 1.3 & NS \\
\hline Speed & $1.46(0.56)$ & I.3I(0.49) & $0.15(0.19)$ & 0.79 & NS \\
\hline Gait Quality (Tinetti)** & $13.9(0.28)$ & $13.57(0.32)$ & $0.33(0.18)$ & 1.83 & NS \\
\hline \multicolumn{6}{|l|}{ Balance } \\
\hline \multicolumn{6}{|l|}{ Berg Balance Scale (Selected Items) } \\
\hline 360 o turn (norm $<4$ secs) & $1.90(0.56)$ & $2.08(0.5 \mathrm{I})$ & $-0.17(0.195$ & -0.89 & NS \\
\hline $\begin{array}{l}\text { Alternate foot to step }(4 \times / \text { foot }) \text { norm }<20 \\
\text { secs) }\end{array}$ & $6.18(0.94)$ & $6.77(1.33)$ & $-0.59(0.42)$ & -1.39 & NS \\
\hline Functional reach (norm > 10 inches) & $13.3(1.94)$ & I2.7 (I.8) & $0.57(0.68)$ & 0.83 & NS \\
\hline Tandem: One foot in front (norm $>30$ secs) & $30.0(0)$ & $27.9(5.76)$ & 2.09 (1.49) & 1.41 & NS \\
\hline $\begin{array}{l}\text { One footed balance eyes open ( norm > } 10 \\
\text { secs) }\end{array}$ & 9.89 (1.58) & $9.85(0.59)$ & $-0.25(0.44)$ & -0.58 & NS \\
\hline
\end{tabular}

*Safe, fast walk.

**Added additional item on symmetry of arm swing bringing total score to 14 .

Participants with mild to moderate PD and age matched controls performed similarly and within normal limits on gait speed, gait quality, 360 o turning time, alternating foot stepping, functional reach, tandem balance and one footed balance.

\section{Primary outcome measurement:TUG}

Both age matched and PD participants completed the TUG (seconds) within age referenced performance levels (7.28age matched and 7.60PD seconds). These performance levels were not significantly different between the two groups of participants.

\section{Secondary balance measurements}

For the subgroup of participants completing the additional balance tests, performance levels on the FTSTS and the i TUG (no dual tasking, carrying water or counting) were within normal limits for both groups. There was no significant group difference in performance on neither the FTSTS nor the single task i TUG. However the overall timed dual task I TUG scores were significantly slower $(\mathrm{p}<0.05)$ for the participants with PD (7.75 seconds ${ }_{\text {arrying water }}$ and 7.06 Seconds ) compared to the age matched participants (6.12 seconds carrying water and 5.86 seconds counting backwards $_{\text {(T) }}$ (Table 4) (Table 5).

\section{Discussion}

The null hypothesis for this study must be accepted. There were no significant differences in performance on the TUG between ages matched controls and patients with early PD. Thus, the TUG cannot on selected items from the Berg Balance Test were within the age normative limits with no significant differences between the two groups (e.g. turning time, alternate stepping, functional reach, tandem balance, one footed balance) (Table 3 ). 
intensely than the age matched controls. Seven of 15 controls were exercising between 120 and 180 minutes per week. Only 5 of the 15 PD participants were exercising between 120 and 180 minutes per week. Eight of the 15 PD participants were exercising over 300 minutes/week. When the 3PD participants with PD who were exercising $>600$ minutes/week were removed from the calculation of the mean exercise level, the patients with PD were still exercising significantly more intensely than age matched controls (233 minutes/ week). To determine the benefits of exercise for maintaining mobility and balance, this study would need to be repeated with a large sample of age matched controls and participants with mild to moderate PD who participated in a broad range of exercise levels (e.g. less than, equivalent to and more than the 120-150 minutes/week as recommended by the Center for Disease Control).

Table 4 TUG and Component TUG (iTUG) with and Without Dual Tasking (Counting Backwards and Carrying Water)

\begin{tabular}{|c|c|c|c|c|c|c|c|c|}
\hline Conditions & I Stand & 2 Step & 3 walk & 4 Turn & 5 Walk & 6 Turn & 7 Sit & Total \\
\hline \multicolumn{9}{|l|}{$\begin{array}{l}\text { Single Task TUG (seconds) } \\
(\mathrm{N}=24)\end{array}$} \\
\hline Age Matched Mean (SD) & $0.81(0.196)$ & $0.59(0.12)$ & $\begin{array}{l}1.34 \\
(0.36)\end{array}$ & $\begin{array}{l}0.98 \\
(0.32)\end{array}$ & $\begin{array}{l}1.92 \\
(0.32)\end{array}$ & $\begin{array}{l}0.66 \\
(0.186)\end{array}$ & $\begin{array}{l}0.57 \\
(0.12)\end{array}$ & $6.87(1.11)$ \\
\hline PD Mean (SD) & $0.83(0.25)$ & $0.59(0.11)$ & $\begin{array}{l}1.44 \\
(0.37)\end{array}$ & $\begin{array}{l}1.14 \\
(0.40)\end{array}$ & $\begin{array}{l}2.04 \\
(0.40)\end{array}$ & $\begin{array}{l}0.72 \\
(0.24)\end{array}$ & $\begin{array}{l}0.61 \\
(0.16)\end{array}$ & $7.38(1.43)$ \\
\hline Mean Diff AM-PD (SD) & $-0.02(0.08)$ & $\begin{array}{l}-(0.002) \\
(0.09)\end{array}$ & $\begin{array}{l}-0.10 \\
(0.125)\end{array}$ & $\begin{array}{l}-0.154 \\
(0.13)\end{array}$ & $\begin{array}{l}-0.12 \\
(0.13)\end{array}$ & $\begin{array}{l}0.05 \\
(0.08)\end{array}$ & $\begin{array}{l}-0.002 \\
(0.06)\end{array}$ & $-0.64(0.44)$ \\
\hline T Test Significance & -0.25 & -0.02 & -0.8 & -1.18 & -0.92 & 0.6 & 0.03 & $-1.45 \mathrm{NS}$ \\
\hline \multicolumn{9}{|l|}{ Dual Task Water(seconds) } \\
\hline Age Matched Mean (SD) & $0.93(0.31)$ & $0.59(0.2 \mathrm{I})$ & $\begin{array}{l}1.17 \\
(0.31)\end{array}$ & $\begin{array}{l}0.97 \\
(0.27)\end{array}$ & $\begin{array}{l}1.52 \\
(0.22)\end{array}$ & $\begin{array}{l}0.82 \\
(0.47)\end{array}$ & $\begin{array}{l}0.59 \\
(0.14)\end{array}$ & $6.60(0.81)$ \\
\hline PD Mean (SD) & $1.06(0.24)$ & $0.68(0.16)$ & $\begin{array}{l}1.54 \\
(0.49)\end{array}$ & $\begin{array}{l}1.46 \\
(0.43)\end{array}$ & $\begin{array}{l}1.82 \\
(0.35)\end{array}$ & $\begin{array}{l}1.05 \\
(0.50)\end{array}$ & $\begin{array}{l}0.685 \\
(0.16)\end{array}$ & $8.30(1.06)$ \\
\hline Mean Difference (AM-PD) & $-0.14(0.13)$ & $-0.04(0.09)$ & $\begin{array}{l}-0.56 \\
(0.38)\end{array}$ & $\begin{array}{l}-0.43 \\
(0.49)\end{array}$ & $\begin{array}{l}-0.31 \\
(0.30)\end{array}$ & $\begin{array}{l}-0.12 \\
(0.24)\end{array}$ & $\begin{array}{l}-0.07 \\
(0.096)\end{array}$ & $-1.57(0.44)$ \\
\hline T Test Significance & -0.65 & -0.68 & -1.47 & -1.95 & -1.5 & -0.68 & -0.92 & -3.56 Sign \\
\hline \multicolumn{9}{|l|}{ Dual Task Counting } \\
\hline Age Matched Mean (SD) & $1.05(0.17)$ & $0.57(0.07)$ & $\begin{array}{l}1.00 \\
(0.32)\end{array}$ & $\begin{array}{l}0.94 \\
(0.18)\end{array}$ & 1.39 & $\begin{array}{l}1.32 \\
(0.38)\end{array}$ & $\begin{array}{l}0.53 \\
(0.09)\end{array}$ & $6.78(0.29)$ \\
\hline PD Mean (SD) & $1.19(0.29)$ & $0.67(0.14)$ & $\begin{array}{l}1.48 \\
(0.48)\end{array}$ & $\begin{array}{l}1.25 \\
(0.41)\end{array}$ & $\begin{array}{l}1.78 \\
(0.46)\end{array}$ & $\begin{array}{l}0.96 \\
(0.46)\end{array}$ & $\begin{array}{l}0.62 \\
(0.11)\end{array}$ & $7.89(1.24)$ \\
\hline Mean Difference (AM-PD) & $\begin{array}{l}-0.128 \\
(0.21)\end{array}$ & $-0.102(0.12)$ & $\begin{array}{l}-0.479 \\
(0.18)\end{array}$ & $\begin{array}{l}-0.309 \\
(0.24)\end{array}$ & $\begin{array}{l}-0.392 \\
(0.24)\end{array}$ & $\begin{array}{l}0.358 \\
(0.38)\end{array}$ & $\begin{array}{l}-0.09 \\
(0.09)\end{array}$ & $-1.11(0.43)$ \\
\hline T Test Significant & -0.6 & -0.83 & -2.61 & -1.28 & -1.65 & 0.95 & -1.04 & -2.58 Sign \\
\hline
\end{tabular}

Note On the standardized TUG, both age matched controls and those with mild to moderate PD performed within normal limits (7.28 [1.03] sec and 7.60 [I.5I] seconds).

On the single task iTUG there were no significant differences in performance for participants with mild to moderate PD and age matched controls. On the dual task iTUG, both age matched controls and participants with PD performed within normal limits. However age matched controls performed the two dual task iTUG more efficiently than participants with mild to moderate PD. Age matched controls also walked faster on the first I0 feet component of the iTUG while counting.

Table 5 iTUG Mean Walk Time (I0 feet) and iTUG Mean Turn Time (360o) Compared to I0 Meter Walk Time and Isolated 360o Turning

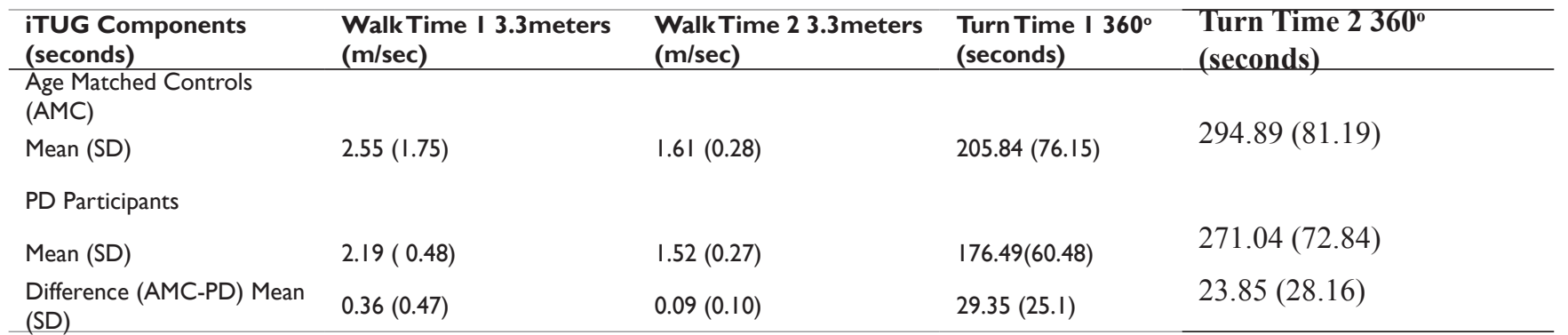


Table Continued

\begin{tabular}{|c|c|c|c|c|}
\hline $\begin{array}{l}\text { iTUG Components } \\
\text { (seconds) }\end{array}$ & $\begin{array}{l}\text { Walk Time I 3.3meters } \\
(\mathrm{m} / \mathrm{sec})\end{array}$ & $\begin{array}{l}\text { Walk Time } 2 \text { 3.3meters } \\
(\mathrm{m} / \mathrm{sec})\end{array}$ & $\begin{array}{l}\text { Turn Time I } 360^{\circ} \\
\text { (seconds) }\end{array}$ & $\begin{array}{l}\text { Turn Time } 2360^{\circ} \\
\text { (seconds) }\end{array}$ \\
\hline $\mathrm{T}$ test & 0.77 & 0.92 & 1.16 & 0.85 \\
\hline Sign & NS & NS & NS & NS \\
\hline $\begin{array}{l}\text { I0 Meter Walk Velocity }(\mathrm{m} / \\
\mathrm{sec})\end{array}$ & & & \multicolumn{2}{|c|}{ Isolated 360 Turning Speed Degree/sec } \\
\hline \multicolumn{5}{|l|}{ Age Matched (AMC) } \\
\hline Mean (SD) & $2.16(0.38)$ & $1.56(0.23)$ & $186.6(61.8)$ & $275.0(60.45)$ \\
\hline \multicolumn{5}{|l|}{ PD Participants (PD) } \\
\hline Mean (SD) & $2.2(0.44)$ & $1.53(0.29)$ & I 68.4 (46.2) & $257.2(67.46)$ \\
\hline $\begin{array}{l}\text { Difference (AMC-PD) Mean } \\
\text { (SD) }\end{array}$ & $0.04(0.17)$ & $0.03(0.26)$ & $18.2(69.9)$ & $17.8(64.5)$ \\
\hline$T$ test & 0.24 & 0.12 & 0.26 & 0.28 \\
\hline Sign & NS & NS & NS & NS \\
\hline
\end{tabular}

Both healthy age matched participants and participants with PD walked more slowly on the return walk back to the chair on the three iTUG tests and the first turn was slower than the second turn as they approached sitting in the chair. Although the differences were not significant, participants with PD turned more quickly than age matched controls.

Interestingly, those with $\mathrm{H}$ and $\mathrm{Y}$ level II exercised an average of 508 minutes/week. The descriptive correlation between exercise level and the Hoehn and Yahr scores was 0.5939 (Spearman Rank Correlation). This correlation suggests those with higher $\mathrm{H}$ and $\mathrm{Y}$ scores were exercising more intensely per week than those classified as $\mathrm{H}$ and $\mathrm{Y}$ Level I. It is not clear if each participant independently discovered they felt better when they exercised or whether the individual read about the benefits of exercise and were self-directed to exercise more or whether their physician recommended more aggressive exercise. A large randomized controlled trial comparing the neuroprotective benefits of comprehensive exercise program that integrates gait training, cardiovascular, strengthening, range of motion, balance, sensorimotor, fine motor and cognitive exercises. ${ }^{62}$

Dopamine medications modify some but not all motor and nonmotor signs and symptoms of PD. Thus, taking dopamine medications may interfere with the ability to distinguish patients with mild PD from age matched control individuals. To determine the contribution of the dopamine medications to mobility and balance performance, another study is needed which would include age matched controls, individuals with mild to moderate PD who were not taking dopaminergic medications and similar PD patients who were taking dopaminergic medications.

There was an interesting secondary finding in this study. The Timed Up and Go Test (TUG) is a standardized clinical measurement of balance applied across a broad base of elderly patients with and without known neurological disease. ${ }^{63,64}$ This pilot study suggests the standardized TUG is not very sensitive in measuring differences between older individuals with or without mild PD. The TUG does not integrate dual tasking and it is usually performed in most clinics using a stopwatch which makes it difficult to time the different components of the test. Even when a lap stopwatch is used, more than one evaluator is needed to assure accuracy when timing the components. Today there are a number of computer generated tests for the TUG where sensors are placed on the extremities to document time and acceleration.

\section{Study limitations}

There were a number of limitations to this study. First, the number of participants was small and not randomly selected from the population at large, limiting generalizability to all people with mild to moderate PD. Considering patients with a Hoehn and Yahr Score between I to II as representative of mild to moderate PD was a subjective reference. There may not be an "average patient with mild to moderate PD". The participants with PD in this study may have been unique based on the self- reported level of exercise. ${ }^{65}$ Although the focus of this study was on participant performance on the TUG, multiple standardized balance measurements were administered to all participants (Functional Reach, 360o turning, one footed balance, tandem romberg). All participants with PD and healthy age matched controls performed these tests within normal limits. Thus, it may be the participants were generally fit, despite PD and had above average performance. This is a limitation if the TUG or i TUG is used in an intervention study given it would be unlikely to measure and minimally clinically significant gain following treatment. The MDC for patients with Parkinson's disease is reported to be 3.5 seconds. ${ }^{66}$

Another limitation of this study was the individuals with PD included in this study may not have represented a typical individual with mild to moderate PD. ${ }^{67}$ This would make it difficult to replicate the study findings. This study was a cross sectional descriptive study and not a longitudinal study. It would be informative to determine if, over time, the performance on the TUG and the iTUG deteriorated for all participants because of age or whether deterioration would have been uniquely more severe in those with PD. Although all participants were invited to return for additional balance testing at no cost, only $70 \%$ of the participants in both groups returned for testing with the i TUG and the FTSTS. There may have been something unusual about those who agreed to return for the additional testing, raising question about the representativeness of the cooperative group.

\section{Summary and conclusion}

This pilot study provides evidence individuals with mild to moderate PD who take dopamine medications and exercise regularly and frequently perform within normal limits on the TUG Test and similar to age matched controls. To differentiate individuals with mild to moderate PD from age matched controls, balance assessment would be more sensitive as a clinical biomarker with dual tasking and component analysis using the instrumental TUG (i TUG). 


\section{Acknowledgments}

None.

\section{Conflict of interest}

The author declares no conflict of interest.

\section{References}

1. Darweesh SK, Koudstaal PJ, Ikram MA. Trends in the incidence of Parkinson disease. JAMA Neurol. 2016;73:1497.

2. Dorsey ER, Constantinescu R, Thompson JP, et al. Projected number of people with Parkinson disease in the most populous nations, 2005-2030. Neurology. 2007;68(5):384-386.

3. Rossi A, Berger K, Chen H, et al. Projection of the prevalence of Parkinson's disease in the coming decades: Revisited. Mov Disord. 2018;33(1):156-159.

4. Savica R, Grossardt BR, Bower JH, et al. Time Trends in the incidence of Parkinson disease. JAMA Neurol. 2016;73(8):981-989.

5. Adler, $\mathrm{CH}$, Beach TG. Neuropathological basis of nonmotor manifestations of Parkinson's disease. Mov Disord. 2016;31(8): 1114-1119.

6. Postuma RB, Berg D, Stern M, et al. MDS clinical diagnostic criteria for Parkinson's disease. Mov Disord. 2015;30(12):1591-1601.

7. Cheng, HC, Ulane CM, Burke RE. Clinical progression in Parkinson disease and the neurobiolgy of axons. Ann Neurol. 2010; 67(6):715-725.

8. Marsden CD. Parkinson's disease. Lancet. 1990;335(8695):948-952.

9. Dauer W, Przedborski S. Parkinson's disease: mechanisms and models Neuron. 2003;39(11):889-909.

10. Moorish PK, Rakshi JS, Bailey DL, et al.. Measuring the rate of progression and estimating the preclinical period of Parkinson's disease with [8F]dopa PET. J Neurol Neurosurg Psychiatry. 1998;64(3):314-319.

11. Keus SHJ, Munneke M, Nijkrake MJ, et al. Physical therapy in Parkinson's disease: Evolution and future challenges. Mov Disord. 2008;24(1):1-14.

12. Martens KAE, Lukasik EL, Geogiades MJ, et al. Predicting the onset of freezing of gait: A longituinal study. Mov Disor. 2018;33(1):128-145.

13. Nonnekes J, Snijders AH, Nutt JG, et al. Freezing of gait: a practical approach to management. Lancet Neurol. 2015;14(7):768-778.

14. Berg D, Postuma RB, Bloem B, et al. Time to redefine PD? Introductory statement of the MDS Task Force on the definition of Parkinson's disease. Mov Disord. 2014;29(4):454-462.

15. Goldman JG, Postuma R. Premotor and nonmotor features of Parkinson's disease. Curr Opin Nuerol. 2014;27(4):434-441.

16. Macleod AD, Taylor KS, Counsell CE. Mortality in Parkinson's disease: a systematic review and meta-analysis. Mov Disord. 2014;29(13):16151622 .

17. William GCH, Mason SL, Evans JR, et al. The CamPalGN study of Parkinson's disease: 10 year outlook in an incident population-based cohort. J Neurol Neurosurg Psychiatry. 2013;84(11):1258-1264.

18. Weintraub D, Simuni T, Caspell GC, et al. Cognitive performance and neuropsychiatric symptoms in early, untreated Parkinson's disease. Mov Disord. 2015;30(7):919-927.

19. Sanchez FA, Benito LJ, Luis ED, et al. Rate of cognitive decline in premotor Parkinson's disease: a prospective study (NEDICES). Mov Diord. 2013;28(2):161-168.

20. Adler CH, Beach TG, Hentz JG, et al. Low clinical diagnostic accuracy of early vs advanced Parkinson disease: clinicopathologic study. Neurology. 2014;83(5):406-412.
21. Dickson DW, Braak H, Duda JE, et al. Neuropathological assessment of Parkinson's disease: refining the diagnostic criteria. Lancet Neurol. 2009;8(12):1150-1157.

22. Gelb DJ, Oliver E, Gilman S. Diagnostic criteria for Parkinson disease. Arch Neurol. 1999;56(1):33-39.

23. Hughes AJ, Daniel SE, Kilford L, et al. Accuracy of clinical diagnosis of idiopathic Parkinson's disease. A clinico-pathological study of 100 cases. JNNP. 1992;55(3):181-184.

24. Ahlskog JE. Does vigorous exercise have a neuroprotective effect in Parkinsons Disease. Neurology. 2011;77(3):288-294.

25. Beck A, Steer R, Garbin M. Psychometric Properties of the Beck Depession Inventory: Twenty five years of evaluation. Clinical Psychology Review. 1988;8(1):77-100.

26. Goetz C. CL Using the celebration of 100 years of Parkinson's Essay on the shakig pa;su" Where do we go in the next 200 years?. Mov Disor. 2017;32(12):1651-1652.

27. Noyce AJ, Lees AJ, Schrag AE. The prediagnostic phase of Parkinson's disease. J Neurol Neurosurg Psych. 2016;87(8):871-878.

28. Ascgerui A, Schwarzschild MA. Dietary Antioxidants and Parkinson's Disease. Mov Disord. 2017;32(11):1501-1503.

29. Fullard ME, Xie SX, Marek K, et al. Vitamin D in the Parkinson associated risk syndrome (PARS) Study. Mov Disord. 2017;32(11):1636-1640.

30. Hirsch MA, Farley BG. Exercise and neuroplasticity in persons living with Parkinson's Disease. Eur J Phys Rehabil Med. 2009; 45(2):215-219.

31. Park A, Zid D, Russell J, et al. Effects of a formal exercise program on Parkinson's disease: a pilot study using a delayed start design. Parkinsonism \& related disorders. 2014;20(1):106-111.

32. Suchowersky O, Gronseth G, Perlmutter J, et al. Practice Parameters: Neuroprotective strategies and alternative therapies for Parkinson's disease (an evidence-based review): report of the Quality Standards Subcommittee of the American Academy of Neurology. Neurology. 2006;66(7):976-978.

33. Zigmond MJ, Cameron JL, Leak RK, et al. Triggering endogenous neuroprotective processes through exercise in models of dopamine deficiency. Parkinsonism Relat Disord. 2009;15(3):S42-45.

34. Zigmond MJ, Smeyne RJ. Exercise: is it a neuroprotective and if so, how does it work? Parkinsonism \& related disorders. 2014; 20(1):S123-127.

35. Noyce AJ, Bestwick JP, Silveira MI, et al. Meta analysis of early nonmotor features and risk factors for Parkinson Disease. Ann Neurol. 2012;72(6):893-901.

36. Ornish D, Lin J, Chan J, et al. Effect of comprehensive liefestyle changes on telomerase activity and telomere length in men with biopsy-proven low-risk prostate cancer: 5-year follow-up of a descriptive pilot study. Lancet Oncol. 2013;14(11):1112-1120.

37. Petzinger GM, Fisher BE, McEwen S, Beeler JA, Walsh JP, Jakowec MW Exercise-enhanced neuroplasticity targeting motor andcognitive circuitry in Parkinson's disease. Lancet Neurol. 2013;12(7):716-726.

38. Ridgel AL, Vitek JL, Alberts JL. Forced, not voluntary, exercise improves motor function in Parkinson's Disease patients. Neurorehabil Neural Repair. 2009;23(6):600-608.

39. Vucckovic MG, Li W, Fisher B, et al. Exercise elevates Dopamine D2 Receptor in a Mouse Model of Parkinson's disease: In Vivo imaging with [18F] Fallypride. Mov Disord. 2010;25(16):2777-2784.

40. Yang F, Wolk A, Hakansson N, et al. Dietary antixidants and risk of Parkinson's Disease in two population-based cohorts. Mov Disord. 2017;32(11):1631-1645.

41. Hanganu A, Bedetti C, Degroot C, et al. Mild cognitive impairment is 
linked with faster rate of cortical thinning in patients with Parkinson's disease longitudinally. Brain: a Journal of Neurology. 2014;137(4):1120 1129.

42. Delpont B, Lhommee E, Klinger H, et al. Psychostimulant effect of dopaminergic treatment and addictions in Parkinson's Disease. Mov Disord. 2017;32(11):1560-1573.

43. Fasano A, Canning CG, Hausdorff JM, et al. Falls in Parkinson's Disease: A complex and Evolving picture. Mov Disord. 2017; 32(11):1524-1536.

44. Sethi K. Levodopa unresponsive symptoms in Parkinson disease. Movement Disorders: Official Journal of the Movement Disorder Society. 2008;23:S521-533.

45. Bejjani BP, Arnulf I, Demerer S, et al. Levodopa-induced dyskinesias in Parkinsons's disease: is sensitization reversible? Ann Neurol. 2000;47(5):655-658.

46. Post RM, Rose $H$. Increasing effects of repetitive cocaine administration in the rat. Nature. 1976;260:731-732.

47. Lee CS, Samii A, Sossi V, et al. In vivo positron emission tomographic evidence for compensatory changes in presynaptic dopaminergic nerve terminals in Parkinson's disease. Ann Neurol. 2000;47(4):493-503.

48. Li W, Lao KNP, Rousakis AA, et al. C-PE21 and 18 F-Dopa PET for assessing progression rate in Parkinson's: A Longituinal study. Mov Disor. 2018;33(1):117-126.

49. Snow BJ, Tooyama I, McGeer EG, et al. Human positron emission tomographic [i18F] fluorodopa studies correlate with dopamine cell counts and levels. Ann Neurol. 1993;34(3):324-330.

50. Ribeiro MJ, Vidailhet M, Loc"h C, et al. Dopaminergic function and dopamine tranporter binding assessed with positron emission tomography in Parkinson disease. Arch Neurol. 2002;59(4):580-586.

51. Wu NA, Cai HW, Ge R, et al. Recent progress of imaging agents for Parkinson's Disease. Current Neuropharmacology. 2013; 12(6):551-563.

52. Mellone S, Tacconi C, Chiari L. Validity of a Smartphone-based instrumented Timed Up and Go. Gait \& Posture. 2012;36(1): 163-165.

53. Shumway CA, Brauer S, Woollacott M. Predicting the probability for falls in community-dwelling older adults using the timed up and go test. Physical Therapy. 2000;80(9):896-903.

54. Wall J, Bell C, Campbell S, et al. The timed get-up-and-go test revisited: Measurement of the component tasks. Journal of Rehabilitation Research and Development. 2000; 7(1):109-114.
55. Hawker GA, Mian, S, Kendzerska T. Measures of adult pain: visual analog scale for pain (VAS PAIN),Numeric rating scale for pain (NRS Pain), McGill Pain Questionnaire (MPQ), Short-Form McGill Pain Questionnaire (SF-MPQ), Chronic pain grade scale (CPGS), Short Form-36 Bodily Pain Scale (SF-36 BPS) and measure of intermittent and constant osteoarthritis pain (ICOAP). Arth Care and Research. 2011;63(11):S240-S252.

56. Tinetti Balance and Gait Assessment BODY WORKShfr.com

57. Salarian A, Horak FB, Zampieri C, et al. iTUG, a sensitive and reliable measure of mobility. IEEE Trans Neural Syst Rehabil Eng. 2010;18(3):303-310

58. Duncan RP, Leddy AL, Earhart GM, et al. "Five times sit-to-stand test performance in Parkinson's disease." Arch Phys Med Rehabil. 2011;92(9):1431-1436.

59. Shirley Ryan Ability lab, USA

60. American College of Sports Medicine Position Stand. The recommended quantity and quality of exercise for developing and maintaining cardiorespiratory and muscular fitness and flexibility in healthy adults. Med Sci Sports Exerc. 1998;30(6):975-991.

61. Center for Disease Control [CDC]. 2016.

62. Shu HF, Yantg T, Yu SX, et al. Aerobic exercise for Parkinson 's disease: A systematic review and meta- analysis of randomized controlled trials. PloS One. 2014;9:1-10e.

63. Morris S, Morris ME, Iansek R. Reliability of measurements obtained with the Timed "Up and Go" Test in people with Parkinson's Disease. Phys Ther. 2001;81(2):810-818.

64. Zampieri C, Salarian A, Carlson KP, et al. The instrumented Timed Up and Go test: Potential outcome measure for disease modifying therapies in Parkinson's Disease. Journal of Neurology Neurosurgery and Psychiatry. 2010;81(2):171-176.

65. Miller FL, O Connor DP, Herring MP, et al. Exercise dose, exercise adherence, and associated health outcomes in the TIGER study. Med Sci Sports Exerc. 2014;46(1):69-75.

66. Huang S, Hsieh $\mathrm{C}, \mathrm{Wu} \mathrm{R}$, et al. Minimal detectable change of the timed "up go" test and the dynamic gait index in people with parkinson disease. Phys Ther. 2011;91(1):114-121.

67. Ayan C, Cancela JM, Santiago G, et al. Effects of two different exercise programs on gait parameters in individuals with Parkinson's disease: A pilot study. Gait and Posture. 2014;39(1):648-651. 